\title{
SOCIO-ECONOMIC DIFFERENCES IN PREFERENCES AND WILLINGNESS TO PAY FOR DIFFERENT PROVIDERS OF MALARIA TREATMENT IN SOUTHEAST NIGERIA
}

\author{
OBINNA ONWUJEKWE,* JULIANA OJUKWU, NKOLI EZUMAH, BENJAMIN UZOCHUKWU, NKEM DIKE, AND \\ EZE SOLUDO
}

Gates Malaria Partnership, London School of Hygiene and Tropical Medicine, London, UK; Department of Health Administration and Management, College of Medicine, University of Nigeria, Enugu; Health Policy Research Unit, Department of Pharmacology and

Therapeutics, College of Medicine, University of Nigeria, Enugu; Department of Paediatrics, Ebonyi State University Teaching Hospital, Abakaliki; Department of Sociology and Anthropology, University of Nigeria, Nsukka; Department of Community Medicine, College of Medicine, University of Nigeria, Enugu

\begin{abstract}
This article determined whether there are links between socio-economic status (SES) and preferences of consumers for different strategies for improving timely and appropriate management of malaria. Ranking of preferences and willingness to pay (WTP) for 5 different strategies for improving the management of malaria in Enugu State, southeast Nigeria were elicited from randomly selected respondents. The results showed that the people were also willing to pay for improved management of malaria, though the levels of WTP was dependent on the SES of the respondents, with the poorest SES group willing to pay the least amount of money. Also, the respondents generally mostly preferred timely and appropriate management of malaria through formal public healthcare system. Hence, to decrease the inequity in malaria management and ensure the ready availability of appropriate treatment to the poorest households, the government should increase the availability and accessibility of publicly owned healthcare services, complemented by community-based health services.
\end{abstract}

\section{INTRODUCTION}

The African Heads of State meeting in Abuja, Nigeria on Roll Back Malaria adopted effective management of malaria nearer the home as one of the strategies for malaria control in Africa. ${ }^{1}$ The Home Management of Malaria (HMM) strategy is being promoted for the timely and appropriate management of malaria in sub-Saharan Africa. ${ }^{2}$ The major strategy under HMM is to train householders to better recognize and treat malaria. Around $60 \%$ of all malaria episodes in subSaharan Africa are initially treated through the purchase of drugs from shops and drug peddlers. ${ }^{3}$ These private sellers often lack important knowledge and are influenced by advertising and profit motives. ${ }^{4}$ However, an intervention study showed that improving the knowledge of drug sellers improved their prescribing practice. ${ }^{5}$

Prompt and effective management of malaria has been shown to be a critical element of malaria control. ${ }^{1,6,7}$ Treatment is recommended within at least 24 hours, especially for children under 5 years of age, to prevent progression to severe malaria and death. ${ }^{8}$ However, the limited healthcare facilities that exist in rural Nigeria make it difficult to provide the required good quality malaria management services. ${ }^{9,10}$ In many cases, there is often lack of government monitoring, making quality healthcare provision all the more limited. ${ }^{10}$ Nevertheless, a study has found that many mothers prefer to still seek malaria care for their children in health centers ${ }^{11}$ despite the sub-optimal care provision. ${ }^{12}$

Little is known about the link of socio-economic status to consumers' preferences and levels of willingness to pay (valuation of benefit) for the different strategies for malaria management that exist. Knowing the level of valuation of benefits of different malaria management providers, can aid in im-

* Address correspondence to Obinna Onwujekwe, Gates Malaria Partnership, London School of Hygiene and Tropical Medicine, 49/51 Bedford Square, London, UK WC1B 3DP. E-mail: onwujekwe@ yahoo.co.uk proving product, price, distribution, and promotion. ${ }^{13}$ Strategies that have been suggested to be useful for providing timely, appropriate, and potentially equitable management of malaria within communities include health education to mothers ${ }^{14}$; training of shopkeepers ${ }^{5,10}$; and the use of village or community health workers. ${ }^{15,16}$ However, they are all biomedical determined needs and solutions could be at variance with what the communities really prefer and want.

The ability for successful and sustainable disease control programs depends very much on "listening to the people". ${ }^{17}$ Unless the interventions are geared towards satisfying the preferences of the communities, their success and sustainability to achieve the bio-medically determined aims would be in doubt. It is better to determine consumers' preferences and needs and use the information to guide program design because imposed programs invariably fail as they reflect professional views and may not meet the priorities and aspirations of communities. ${ }^{18}$

It is also important to ensure that strategies that are implemented to improve the management of malaria are equitable and hence, available to the poorest SES groups, because the poor people bear a disproportionate burden of the disease and have poor health-seeking habits. ${ }^{9,19}$ Important socioeconomic differentials exist in access to malaria interventions, increasing the vulnerability of the poorest. ${ }^{20}$ Health inequities are also associated with intra and inter community socioeconomic differences ${ }^{21}$ and malaria is recognized as a disease of poverty and it can depress economic growth. ${ }^{22}$

This article presents findings that are important for understanding the value of benefits that people attach to the different providers of malaria management as well as the potential demand for the different providers. The article also shows how the information could be harnessed for wide-scale and equitable timely and appropriate management of malaria. Hence, it shows the peoples' preferences for different strategies to improve timely provision of appropriate management of malaria, their ranking for the preferred strategies, as well as their level of valuations of benefits for the strategies and whether such are dependent on their socio-economic status. 


\section{RESEARCH METHODS}

Study area. The study areas were 3 malaria hole-endemic communities (towns) in Enugu State, southeast Nigeria, namely Nachi in Udi Local government area (LGA) plus Inyi and Oji-river (Oji) in Oji-River LGA. Oji was the local government headquarters, whereas Nachi and Inyi were not. Oji is a semi-urban area, whereas the other two sites were rural areas. Each town has a population of at least 20,000 people, with majority of the residents being either subsistence farmers or small-time traders. Each town is composed of at least 7 component villages and is an autonomous unit headed by a traditional ruler called "Igwe", who is assisted by a cabinet of traditional ministers.

Oji has a government-owned general hospital and a primary healthcare center, together with private hospitals/clinics to complement the public providers. There is a comprehensive health center and a primary health center is Inyi, whereas Nachi is devoid of the presence of any public healthcare provider. Patent medicine stores, itinerant drug providers, and numerous herbalists abound in these towns. The major malaria vector in these towns is Anopheles Gambiense, while Plasmodium falciparum causes more than $90 \%$ of all malaria cases. $^{23}$

Sampling. Multi-staged sampling was used to select the respondents. In the first stage, 4 component villages were selected from each town. Then a listing of households in each selected village was undertaken to produce the sampling frame. Using the household lists as the sampling frame, 370 households were selected from each community using simple random sampling. In each selected household, one woman (primary caregiver) or in her absence, male head of household was interviewed using a pre-tested questionnaire. An adequate sample size for the study was based on an average malaria incidence rate of $10-15 \%$ in Enugu state, ${ }^{23} 95 \%$ confidence level, and $80 \%$ power was a maximum of 300 respondents in each community. However, to control for refusals and incomplete questionnaires, 370 respondents were selected and approached for interview in each community or question format group as the case may be.

Determination of preferences and elicitation of willingness to pay. The preferences were determined using contingent ranking of different interventions and the strengths of preferences determined using the contingent valuation method by eliciting peoples' maximum willingness to pay (WTP) per full treatment from the different interventions. The interventions presented were: the use of community health workers; education to mothers to improve home treatment; training of patent medicine dealers; improving the quality of services in the government-owned general hospitals, improving the quality of services in government-owned primary healthcare (PHC) centers; and treatment in private hospitals/clinics.

The contingent valuation method (CVM) was used to value benefits, through the elicitation of respondents' maximum willingness to pay (WTP) amounts of money for different healthcare providers. ${ }^{24-26}$ The CVM is a survey-based approach for eliciting the value that people attach to goods and services by determining their maximum WTP for the good or service in question. Proponents of the CVM have argued that it is a valid method for eliciting consumer choices, ${ }^{24,27}$ whereas some people have argued against the CVM because they feel that stated WTP is a poor indicator of actual
WTP $^{28,29}$ with identification of bias. ${ }^{30-32}$ However, many studies have shown that the CVM is an acceptable and valid method for eliciting WTP. ${ }^{27,33,34}$

Scenarios describing the attributes of the different interventions were presented to the respondents before asking them to rank them in order of preference. A visual aid in the form of a multi-colored ruler was used to help the respondents to rank their preferences. All the respondents were asked to rank their preferences for all the different interventions. The ruler progressively increased in size from $0-10$, to illustrate the magnitude of different ranks to the respondents. The respondents were encouraged to consult their spouses before stating their maximum WTP. The bidding game, which is a CVM question format, was used to elicit WTP. The rankings were first determined before WTP was elicited.

Data analysis. Principal components analysis (PCA) was used to generate a household socio-economic status (SES) index ${ }^{8}$ that was used to investigate the equity implications of the findings. Information on ownership of a radio, bicycle, motorcycle, motorcar, refrigerator, together with the weekly household cost of food was used to generate the index. The SES index was used to divide the households into SES tertiles (3 groups), which were then used to determine the equity implications of WTP (demand) for different malaria management strategies. The 3 SES groups were: the highest SES group (Q3) or least poor; middle SES group (Q2) or average; and lowest SES group (Q1) or most poor. We decided to use 3 SES groups instead of the more widely used quintiles or quartiles because the socio-economic class differences in the rural communities are not very dispersed in the study sites because of similar income generation activities at that level.

The decisions and strengths of preferences were disaggregated into SES tertiles to determine whether there are socio-economic differentials in the responses. The ordering of the interventions was randomized across the survey to limit ordering effect in the valuation. Tabulations, testing of means, non-parametric tests and appropriate econometric models for tests of validity were the data analytic tools. $\chi^{2}$ analysis for trend was used to determine the statistical significance of the differentiation of the dependent variables into SES tertiles. Tests of theoretical validity of the estimates of WTP were assessed using ordinary least squares (OLS) multiple regression analyses, with the log transformed levels of WTP being the dependent variable. The monetary results were expressed in the local currency, Naira. Note that 130 Naira $=$ US $\$ 1.00$.

\section{RESULTS}

Socio-economic and demographic characteristics of the respondents and their households. The description of the respondents and their households is presented in Table 1. The number of questionnaires that were complete and acceptable for data analysis in the 3 groups of respondents was 356 in Inyi, 346 in Oji-river (Oji) and 323 in Nachi. Most of the respondents were females and they were either the wives or representatives of the household heads. Majority of the respondents from Oji had some level of formal education, whereas the reverse was the case in Nachi, while Inyi was $50 \%$. The average age of the respondents ranged from 39 years in Oji to 52 years in Nachi. 
TABLE 1

Socio-economic and demographic characteristics

\begin{tabular}{|c|c|c|c|}
\hline & $\begin{array}{c}\text { Inyi } \\
\mathrm{N}=356\end{array}$ & $\begin{array}{c}\text { Ihu } \\
\mathrm{B}=346\end{array}$ & $\begin{array}{c}\text { Nacgu } \\
\mathrm{N}=323\end{array}$ \\
\hline Status (spouse/rep): n (\%) & $309(86.8)$ & $310(89.6)$ & $281(87.0)$ \\
\hline Attended school: n (\%) & $178(50.0)$ & $322(93.1)$ & $126(39.0)$ \\
\hline School years: Mean (SD) & $4.50(5.37)$ & $9.81(5.18)$ & $2.97(4.38)$ \\
\hline Married: n (\%) & $313(87.9)$ & $339(98.0)$ & $311(96.3)$ \\
\hline No. of household residents: Mean (SD) & $6.30(3.45)$ & $5.71(2.10)$ & $3.81(2.14)$ \\
\hline Male: n (\%) & $23(6.5)$ & $18(5.2)$ & $16(5.0)$ \\
\hline Age: Mean (SD) & $42.44(14.45)$ & $39.00(11.21)$ & $51.68(14.49)$ \\
\hline Weekly food value in Naira: Mean (SD) & $2071.9(2313.4)$ & 2014.45 (1618.7) & $983.5(1872.4)$ \\
\hline Own radio set: $\mathrm{n}(\%)$ & $292(82.0)$ & $330(95.4)$ & $279(86.4)$ \\
\hline Own bicycle: n (\%) & $255(71.6)$ & $41(11.8)$ & $136(42.1)$ \\
\hline Own motorcycle: n (\%) & $91(25.6)$ & $86(24.9)$ & $17(5.3)$ \\
\hline Own motorcar: n (\%) & $27(7.6)$ & $61(17.6)$ & $5(1.5)$ \\
\hline Own refrigerator: $\mathrm{n}(\%)$ & $17(4.8)$ & $252(72.8)$ & $23(7.1)$ \\
\hline
\end{tabular}

Note: 130 Naira $=$ US\$1.00

The household food costs were highest in Inyi, whereas the least household food costs were incurred in Nachi. Radio sets were the commonest household movable asset owned by households while motorcar was the least common asset owned by households. Most households from Oji owned refrigerator probably, because the community houses a thermal power station, and hence the residents enjoy regular supply of electricity. There was an even distribution of households into 3 socio-economic status (SES) groups in the 6 study groups.

Table 2 describes the breakdown by socio-economic status (SES) group of the variables that were used to develop the
SES index. The table shows the level of 'validity' of the SES index because if the variables that made up the index clearly show differentiation across the SES groups as expected, then most likely, the SES index will show valid SES differentiation of the focal variables. Table 2 clearly shows that the poorer the household, the lower the level of food costs, which is the proxy of income in this study. The other variables also show statistically significant differentiation across the 3 SES groups, with the ownership of all the assets being least common among the poorest SES and the least poor SES being most likely to own all the household assets.

TABLE 2

Food cost and asset holdings, by socio-economic status group

\begin{tabular}{|c|c|c|c|}
\hline & Inyi & Oji & Nachi \\
\hline \multicolumn{4}{|l|}{ Food costs (Naira) } \\
\hline \multicolumn{4}{|l|}{ Mean (SD) } \\
\hline Q1: most poor & $1314.5(1302.8)$ & 1317.5 (1614.6) & $415.9(343.8)$ \\
\hline Q2: average & $1821.6(748.7)$ & $2117.7(1242.5)$ & $904.4(544.6)$ \\
\hline Q3: least poor & $3088.0(3503.2)$ & 2627.5 (1707.9) & $1647.7(3088.9)$ \\
\hline Chi squre $(P$ value $)$ & $46.9(.0001)$ & $47.4(.0001)$ & $143.3(.0001)$ \\
\hline \multicolumn{4}{|l|}{ Radio n (\%) } \\
\hline Q1: most poor & $58(19.9)$ & $100(30.3)$ & $65(23.3)$ \\
\hline Q2: average & $118(40.4)$ & $118(35.8)$ & $108(28.7)$ \\
\hline Q3: least poor & $116(39.9)$ & $112(33.9)$ & $106(38.0)$ \\
\hline Chi square ( $P$ value $)$ & $134.3(.0001)$ & $33.3(.0001)$ & $100.0(0.001)$ \\
\hline \multicolumn{4}{|l|}{ Bicycle $\mathrm{n}(\%)$} \\
\hline Q1: most poor & $28(11.0)$ & $29(70.7)$ & $4(2.9)$ \\
\hline Q2: average & $115(45.1)$ & $7(17.1)$ & $40(29.4)$ \\
\hline Q3: least poor & $112(43.9)$ & $5(12.2)$ & $92(67.7)$ \\
\hline Chi square ( $P$ value $)$ & $203.6(.0001)$ & $29.0(.0001)$ & $154.0(0.001)$ \\
\hline \multicolumn{4}{|l|}{ Motorcycle n (\%) } \\
\hline Q1: most poor & $3(3.3)$ & $9(10.4)$ & $0(0)$ \\
\hline Q2: average & $5(3.5)$ & $4(4.7)$ & $0(0)$ \\
\hline Q3: least poor & $83(91.2)$ & $73(84.9)$ & $17(100.0)$ \\
\hline Chi square ( $P$ value) & $180.1(.0001)$ & $144.8(.0001)$ & $36.7(0.001)$ \\
\hline \multicolumn{4}{|l|}{ Motorcar n (\%) } \\
\hline Q1: most poor & $1(3.7)$ & $4(6.5)$ & $0(0)$ \\
\hline Q2: average & $0(0)$ & $12(19.7)$ & $0(0)$ \\
\hline Q3: least poor & $26(96.3)$ & $45(73.8)$ & $5(100.0)$ \\
\hline Chi square ( $P$ value) & $52.6(.0001)$ & $59.8(.0001)$ & $10.4(0.01)$ \\
\hline \multicolumn{4}{|l|}{ Refrigerator n (\%) } \\
\hline Q1: most poor & $0(0)$ & $22(8.7)$ & $1(4.3)$ \\
\hline Q2: average & $0(0)$ & $118(46.8)$ & $3(13.1)$ \\
\hline Q3: least poor & $17(100.0)$ & $112(44.5)$ & $19(82.6)$ \\
\hline Chi square ( $P$ value) & $36.0(.0001)$ & $255.9(.0001)$ & $28.1(0.001)$ \\
\hline
\end{tabular}

Note 130 Naira $=$ US $\$ 1.00$ 
Preferences for improved management of malaria. In Oji and Inyi, the majority of the respondents felt that improving the quality of malaria management in government-owned facilities was the best way to appropriately manage malaria in a timely manner. However, respondents from Nachi felt that the use of community health workers is the best strategy for improving the management of malaria. Education to mothers was the second preferred strategy in Oji. Overall, most people did not perceive that the use of private clinics and training patent medicine dealers were good strategies for improving the management of malaria in their communities. Also, in general, the most preferred strategy was management in government general hospitals, followed by community health workers and education to mothers.

There were very few statistically significant socio-economic status (SES) differences in the preferences for provision of improved management of malaria in the 3 groups (Table 3 ). In Oji, the preference for improving the quality of management in government-owned facilities was more with the better-off SES groups $(P<0.05)$. The least poor SES group also mostly preferred receiving treatment in health centers. Surprisingly, the highest numbers of respondents that preferred use of private health facilities in Oji were from the 'most poor' SES group.

Contingent ranking of different methods for improving malaria management. The strategies with the highest ranks in Inyi were improving the quality of malaria management in government- owned general hospitals and health centers. In Nachi, the highest ranks were for the use of community health workers, followed by the improvement of the quality of management in government-owned general hospitals and health centers. However, in Oji, the highest ranking was for education to be given to mothers to improve home management, followed by improved quality of management in governmentowned general hospitals and health centers.

There were many statistically significant socio-economic differences in the contingent ranks in the 3 groups (Table 4), although the relationship between socioeconomic status and the ranks were not in constant linear direction in some of the cases. The highest levels of occurrence of socio-economic differentials were found in Inyi, Oji, and Nachi. In Inyi, it was only the use of community health workers that was not statistically significantly differentiated along SES groups (see Table 4). In the remaining strategies in Inyi, the ranking of the better-off SES groups were higher, although the only linear finding was with respect to training of patent medicine dealers. Similarly in Oji, the least poor SES group gave the highest ranks followed by the average SES group to improvement of quality of management in public primary health centers and use of community health workers, whereas the average SES group, followed by the least poor SES group gave the highest ranks to improving the quality of management in general hospitals and education to mothers. However, in Nachi, the most-poor SES group gave the highest statistically significant ranks for the improvement of quality of management in public general hospitals and training of patent medicine dealers.

Willingness to pay for different providers. Majority of the respondents in Inyi and Oji were willing to pay for improved quality of malaria management in public general hospitals and this was followed by WTP for management in primary healthcare centers in Inyi and Oji (Table 5). In Nachi, the

TABLE 3

Preferences for improved treatment of malaria, by socio-economic group

\begin{tabular}{|c|c|c|c|}
\hline & $\begin{array}{c}\text { Inyi } \\
\text { n (\%) }\end{array}$ & $\underset{\mathrm{n}(\%)}{\mathrm{Oij}}$ & $\begin{array}{l}\text { Nachi } \\
\text { n }(\%)\end{array}$ \\
\hline \multicolumn{4}{|c|}{ Improving the quality of treatment in government general hospitals } \\
\hline Q1: most poor & $24(28.2)$ & $33(21.0)$ & $4(36.4)$ \\
\hline Q2: average & $30(353)$ & $68(43.3)$ & $6(54.5)$ \\
\hline Q3: least poor & $31(36.5)$ & $56(35.7)$ & $1(9.1)$ \\
\hline Chi square ( $P$ value $)$ & $1.4(0.5)$ & $23.0(0.001)$ & $3.5(0.2)$ \\
\hline \multicolumn{4}{|c|}{ Community health workers } \\
\hline Q1: most poor & $16(25.0)$ & $5(62.5)$ & $52(36.6)$ \\
\hline Q2: average & $28(43.8)$ & $1(12.5)$ & $47(33.1)$ \\
\hline Q3: least poor & $20(31.2)$ & $2(25.0)$ & $43(30.3)$ \\
\hline Chi square ( $P$ value $)$ & $4.2(0.1)$ & $3.3(.19)$ & $1.1(0.6)$ \\
\hline \multicolumn{4}{|c|}{ Education to mothers to self-treat } \\
\hline Q1: most poor & $9(19.6)$ & $21(28.8)$ & $19(38.8)$ \\
\hline Q2: average & $20(43.5)$ & $27(37.0)$ & $13(26.5)$ \\
\hline Q3: least poor & $17(36.9)$ & $25(34.2)$ & $17(34.7)$ \\
\hline Chi square ( $P$ value $)$ & $4.9(0.09)$ & $0.95(.62)$ & $1.3(0.5)$ \\
\hline \multicolumn{4}{|c|}{ Treatment in primary healthcare centres } \\
\hline Q1: most poor & $22(37.9)$ & $8(33.3)$ & $14(22.2)$ \\
\hline Q2: average & $16(27.6)$ & $7(29.2)$ & $21(33.3)$ \\
\hline Q3: least poor & $20(34.5)$ & $9(37.5)$ & $28(44.5)$ \\
\hline Chi square ( $P$ value $)$ & $1.2(0.6)$ & $2.3(.69)$ & $6.3(0.04)$ \\
\hline \multicolumn{4}{|c|}{ Train patent medicine dealers } \\
\hline Q1: most poor & $11(37.9)$ & $5(35.7)$ & $10(20.8)$ \\
\hline Q2: average & $8(27.6)$ & $3(21.4)$ & $24(50.0)$ \\
\hline Q3: least poor & $10(34.5)$ & $6(42.9)$ & $14(29.2)$ \\
\hline Chi square ( $P$ value $)$ & $0.5(0.8)$ & $1.2(.55)$ & $7.6(0.02)$ \\
\hline \multicolumn{4}{|c|}{ Private hospitals and clinics } \\
\hline Q1: most poor & $6(30.0)$ & $18(58.1)$ & $0(0)$ \\
\hline Q2: average & $9(45.0)$ & 4 (12.9) & $1(100.0)$ \\
\hline Q3: least poor & $5(25.0)$ & $9(29.0)$ & $0(0)$ \\
\hline Chi square ( $P$ value $)$ & $1.3(0.5)$ & $10.7(.005)$ & $2.0(0.4)$ \\
\hline
\end{tabular}


TABLE 4

Contingent ranking of different methods for improving malaria treatment, by socio-economic status

\begin{tabular}{|c|c|c|c|}
\hline & $\begin{array}{c}\text { Inyi } \\
\text { Mean (SD) }\end{array}$ & $\begin{array}{c}\mathrm{Oji} \\
\text { Mean (SD) }\end{array}$ & $\begin{array}{c}\text { Nachi } \\
\text { Mean (SD) }\end{array}$ \\
\hline \multicolumn{4}{|c|}{ Improve quality of treatment in government general hospitals } \\
\hline Q1: most poor & $6.3(3.6)$ & $5.1(3.7)$ & $6.7(3.4)$ \\
\hline Q2: average & $7.8(2.2)$ & $7.9(3.1)$ & $5.5(3.7)$ \\
\hline Q3: least poor & $7.2(2.4)$ & $7.6(3.2)$ & $6.1(3.7)$ \\
\hline Chi square $(P$ value $)$ & $7.3(.03)$ & $48.1(.01)$ & $6.3(0.04)$ \\
\hline \multicolumn{4}{|c|}{ Community health workers } \\
\hline Q1: most poor & $5.7(3.5)$ & $3.6(2.9)$ & $6.4(3.2)$ \\
\hline Q2: average & $6.6(3.1)$ & $2.8(3.0)$ & $6.6(3.2)$ \\
\hline Q3: least poor & $6.5(2.8)$ & $3.8(3.2)$ & $6.1(3.3)$ \\
\hline Chi square ( $P$ value $)$ & $4.40(.11)$ & $7.7(.02)$ & $1.9(0.4)$ \\
\hline \multicolumn{4}{|c|}{ Education to mothers to self-treat } \\
\hline Q1: most poor & $4.6(3.0)$ & $6.4(3.5)$ & $5.0(3.5)$ \\
\hline Q2: average & $6.1(2.6)$ & $8.2(2.2)$ & $5.3(3.6)$ \\
\hline Q3: least poor & $5.9(2.7)$ & $7.5(2.9)$ & $5.3(3.8)$ \\
\hline Chi square ( $P$ value $)$ & $17.2(.0001)$ & $14.1(.01)$ & $0.9(0.6)$ \\
\hline \multicolumn{4}{|c|}{ Treatment in primary healthcare centers } \\
\hline Q1: most poor & $6.3(3.3)$ & $5.1(3.1)$ & $6.0(3.9)$ \\
\hline Q2: average & $7.6(2.2)$ & $6.7(2.2)$ & $5.7(4.1)$ \\
\hline Q3: least poor & $7.3(2.4)$ & $6.7(2.5)$ & $4.8(3.9)$ \\
\hline Chi square ( $P$ value) & $7.2(.03)$ & $18.2(.001)$ & $4.2(0.1)$ \\
\hline \multicolumn{4}{|c|}{ Training of patent medicine dealers } \\
\hline Q1: most poor & $5.3(3.1)$ & $3.5(3.0)$ & $5.2(3.1)$ \\
\hline Q2: average & $6.3(2.0)$ & $4.1(2.9)$ & $4.2(2.9)$ \\
\hline Q3: least poor & $6.6(2.4)$ & $3.9(3.3)$ & $4.6(2.9)$ \\
\hline Chi square ( $P$ value $)$ & $8.1(.02)$ & $2.4(.30)$ & $11.0(0.001)$ \\
\hline \multicolumn{4}{|c|}{ Treatment in private clinics and hospitals } \\
\hline Q2: most poor & $5.8(3.1)$ & $4.0(3.0)$ & $5.4(3.2)$ \\
\hline Q2: average & $7.4(1.8)$ & $6.2(2.5)$ & $4.2(2.9)$ \\
\hline Q3: least poor & $7.2(2.3)$ & $5.6(2.7)$ & $4.6(2.9)$ \\
\hline Chi square $(P$ value $)$ & $15.0(.001)$ & $41.3(.01)$ & $9.5(0.01)$ \\
\hline
\end{tabular}

majority of the people were willing to pay to receive treatment from community health workers. Overall, the least proportion of decisions to state a positive WTP was to receive treatment from trained patent medicine dealers.

The levels of WTP matched the decisions to state a positive
WTP (see Table 5). This means that healthcare provision strategies that had a majority of people that were willing to pay positive amounts of money also had the highest levels of WTP. For instance, it was seen that mean WTP for improved quality of services in public general hospitals, when compared

TABLE 5

Willingness to pay for different providers (Naira)

\begin{tabular}{|c|c|c|c|}
\hline & Inyi & $\mathrm{Oji}$ & Nachi \\
\hline $\begin{array}{l}\text { Whether willing to pay for improved quality } \\
\text { of malaria treatment in general hospitals is improved: } \mathrm{n}(\%)\end{array}$ & $199(55.9)$ & $127(36.7)$ & $135(41.8)$ \\
\hline \multicolumn{4}{|l|}{$\begin{array}{l}\text { Level of willingness to pay (WTP) for improved } \\
\text { quality of malaria treatment in general hospitals }\end{array}$} \\
\hline Mean & 522.9 & 373.6 & 362.0 \\
\hline Median (SD) & $530.0(657.5)$ & $400.0(236.2)$ & $400.0(282.1)$ \\
\hline Whether willing to pay for treatment by community health workers: $\mathrm{n}(\%)$ & $173(48.6)$ & $55(15.9)$ & $214(66.3)$ \\
\hline \multicolumn{4}{|l|}{ Level of WTP to pay for treatment by community health workers } \\
\hline Mean & 423.4 & 245.2 & 563.6 \\
\hline Median (SD) & $500.0(334.4)$ & $200.0(193.5)$ & $600.0(353.3)$ \\
\hline Whether willing to pay for improved treatment in primary healthcare centers: $\mathrm{n}(\%)$ & 198 (55.6) & $110(31.8)$ & $135(41.8)$ \\
\hline \multicolumn{4}{|l|}{ Level of WTP for treatment in primary healthcare centers } \\
\hline Mean & 470.0 & 331.4 & 392.4 \\
\hline Median (SD) & $500.0(355.6)$ & $300.0(238.1)$ & $450.0(273.3)$ \\
\hline Whether willing to pay to receive treatment from trained patent medicine dealers: $\mathrm{n}(\%)$ & $122(34.3)$ & $47(13.6)$ & $169(52.3)$ \\
\hline \multicolumn{4}{|l|}{ Level of WTP to trained shopkeepers and patent medicine dealers } \\
\hline Mean & 313.1 & 208.4 & 442.3 \\
\hline Median (SD) & $250.0(287.2)$ & $150.0(188.8)$ & $500.0(275.6)$ \\
\hline Whether willing to pay for treatment in private clinics and hospitals: $\mathrm{n}(\%)$ & $180(50.6)$ & $100(28.9)$ & $171(52.9)$ \\
\hline \multicolumn{4}{|l|}{ Level of WTP to pay for treatment in private clinics and hospitals } \\
\hline Mean & 452.3 & 317.0 & 430.5 \\
\hline Median (SD) & $500.0(342.7)$ & $300.0(235.7)$ & $500.0(283.3)$ \\
\hline
\end{tabular}


TABLE 6

Number of people willing to pay positive amounts of money by socio-economic status

\begin{tabular}{lccr}
\hline & Inyi & Oji & Nachi \\
& $\mathrm{n}(\%)$ & $\mathrm{n}(\%)$ & \\
\hline General hospitals & & & \\
Q1: most poor & $51(25.6)$ & $43(33.9)$ & $34(25.2)$ \\
Q2: average & $76(38.2)$ & $44(34.6)$ & $55(40.7)$ \\
Q3: least poor & $72(36.2)$ & $40(31.5)$ & $46(34.1)$ \\
Chi square $(P$ value $)$ & $12.5(0.002)$ & $0.07(0.97)$ & $8.8(0.01)$ \\
Community health workers & & & \\
Q1: most poor & $51(29.5)$ & $23(41.8)$ & $59(27.6)$ \\
Q2: average & $64(37.0)$ & $14(25.5)$ & $78(36.4)$ \\
Q3: least poor & $58(33.5)$ & $18(32.7)$ & $77(36.0)$ \\
Chi square $(P$ value $)$ & $2.9(0.2)$ & $2.8(.25)$ & $10.8(0.001)$ \\
Primary healthcare centers & & & \\
Q1: most poor & $55(27.7)$ & $39(35.5)$ & $35(25.9)$ \\
Q2: average & $73(36.9)$ & $34(30.9)$ & $48(35.6)$ \\
Q3: least poor & $70(3.4)$ & $37(33.6)$ & $52(38.5)$ \\
Chi square $(P$ value $)$ & $6.5(0.04)$ & $0.74(.69)$ & $6.8(0.03)$ \\
Patent medicine dealers & & & \\
Q1: most poor & $36(29.5)$ & $19(40.4)$ & $44(26.0)$ \\
Q2: average & $45(36.9)$ & $15(31.9)$ & $62(36.7)$ \\
Q3: least poor & $41(33.6)$ & $13(27.7)$ & $63(27.3)$ \\
Chi square $(P$ value $)$ & $1.5(0.5)$ & $1.2(.54)$ & $9.5(0.01)$ \\
Private hospitals & & & \\
Q1: most poor & $50(27.8)$ & $36(36.0)$ & $41(24.0)$ \\
Q2: average & $65(36.1)$ & $31(31.0)$ & $66(38.6)$ \\
Q3: least poor & $65(36.1)$ & $33(33.0)$ & $64(37.4)$ \\
Chi square $(P$ value $)$ & $5.2(0.07)$ & $0.67(.72)$ & $15.5(0.00)$ \\
\hline
\end{tabular}

with WTP for other healthcare provision strategies was the highest in Inyi and Oji and the figures were 523 Naira (\$4.02) and 374 Naira (\$2.88) in the two communities. In Nachi, the highest mean WTP was for treatment by community health workers at 564 Naira (\$4.34). In general, the better-off SES was more willing to pay than others and also stated higher levels of WTP for malaria management (Tables 6 and 7). However, in some of the cases in which there were statistically significant differentiations of WTP according to SES groups, the finding was not monotonic.

Many variables explained the individual WTP in the multiple regression analysis, although not uniformly across the 6 study groups and 5 malaria treatment options. The key results are presented in Table 8. Socio-economic status was statistically significant with respect to WTP for patent medicine dealers in Oji and WTP for community health workers in Inyi. All in all, all the regression analyses were statistically significant and on the average, they explained more than $40 \%$ of the variations in WTP as inferred from the adjusted R-squared.

\section{DISCUSSION}

From the examination of the ranking of preferences, one could argue that improvement in quality of treatment in public facilities and use of community health workers are the interventions that would mostly improve equity in the management of malaria. The other strategies could still be used as adjuncts, but the greatest efforts and resources should be channeled into the improvement of the number, access to, and quality of malaria treatment services in public facilities. Improving the quality and performance of the public healthcare facilities was same strategy that was used in countries of Southeast Asia where malaria has been successfully controlled $^{35}$ and it is the best method that should be applied to the study communities, Nigeria, and in sub-Saharan Africa.

The peoples' preferences for improved management of malaria could imply that people feel that it is the obligation of government to provide malaria treatment services. On the other hand one could also argue that people are more confi-

TABLE 7

Levels of willingness to pay by socio-economic status (Naira)

\begin{tabular}{|c|c|c|c|}
\hline & $\begin{array}{c}\text { Inyi } \\
\text { Mean (SD) }\end{array}$ & $\begin{array}{c}\mathrm{Oji} \\
\text { (Mean (SD) }\end{array}$ & $\begin{array}{c}\text { Nachi } \\
\text { Mean (SD) }\end{array}$ \\
\hline \multicolumn{4}{|l|}{ General hospitals } \\
\hline Q1: most poor & $372.3(310.6)$ & $337.8(239.7)$ & $293.6(279.6)$ \\
\hline Q2: average & $624.7(851.2)$ & $393.6(205.6)$ & $423.4(284.7)$ \\
\hline Q3: least poor & $572.1(669.0)$ & $389.6(259.4)$ & $369.9(268.7)$ \\
\hline Chi square $(P$ value $)$ & $18.37(.0001)$ & $3.1(.2)$ & $11.3(0.001)$ \\
\hline \multicolumn{4}{|c|}{ Community health workers } \\
\hline Q1: most poor & $324.0(283.3)$ & $223.4(216.9)$ & $477.5(354.3)$ \\
\hline Q2: average & $479.7(347.2)$ & $257.8(175.8)$ & $607.1(339.2)$ \\
\hline Q3: least poor & $467.0(348.8)$ & $254.6(185.4)$ & $607.8(353.2)$ \\
\hline Chi square ( $P$ value $)$ & $16.57(.0001)$ & $6.00(.01)$ & $8.9(0.01)$ \\
\hline \multicolumn{4}{|c|}{ Primary healthcare centers } \\
\hline Q1: most poor & $375.0(300.9)$ & $312.8(224.1)$ & $342.2(277.1)$ \\
\hline Q2: average & $505.4(351.4)$ & $328.0(28.0)$ & $401.1(235.0)$ \\
\hline Q3: least poor & $530.1(392.2)$ & $354.3(270.6)$ & $435.0(299.0)$ \\
\hline Chi square ( $P$ value $)$ & $12.8(.002)$ & $1.10(.60)$ & $6.8(.03)$ \\
\hline \multicolumn{4}{|l|}{ Patent medicine dealers } \\
\hline Q1: most poor & $256.5(251.6)$ & $184.2(195.8)$ & $397.5(297.8)$ \\
\hline Q2: average & $337.1(276.8)$ & $233.5(181.8)$ & $452.5(259.2)$ \\
\hline Q3: least poor & 346.1 (322.8) & $207.1(187.0)$ & $477.9(264.3)$ \\
\hline Chi square $(P$ value $)$ & $8.9(.012)$ & $8.2(.01)$ & $5.5(0.06)$ \\
\hline \multicolumn{4}{|l|}{ Private hospitals } \\
\hline Q1: most poor & $355.4(288.5)$ & $291.1(227.8)$ & $358.7(294.6)$ \\
\hline Q2: average & $450.9(277.8)$ & $314.4(206.8)$ & $461.0(276.5)$ \\
\hline Q3: least poor & $551.4(418.4)$ & $346.4(268.7)$ & $473.2(266.1)$ \\
\hline Chi square ( $P$ value $)$ & $17.3(.0001)$ & $2.0(.4)$ & $11.4(0.001)$ \\
\hline
\end{tabular}


TABLE 8

Ordinary least squares multiple regression analyses for determinants of WTP willingness to pay

\begin{tabular}{|c|c|c|c|}
\hline & $\begin{array}{c}\text { Inyi } \\
\text { Coeff (SD) }\end{array}$ & $\begin{array}{c}\mathrm{Oji} \\
\text { (Coeff (SD) }\end{array}$ & $\begin{array}{c}\text { Nachi } \\
\text { Coeff (SD) }\end{array}$ \\
\hline \multicolumn{4}{|l|}{ General hospitals } \\
\hline Socio-economic status & $.02(.03)$ & $-.02(.02)$ & $.01(.03)$ \\
\hline Education & $.01(.01)$ & $.01(.006) *$ & $-.02(.13)$ \\
\hline Marital status & $-.11(.13)$ & $.02(.20)$ & $-.04(.20)$ \\
\hline Respondent had recent malaria & $-.01(.06)$ & $.01(.06)$ & $-.14(.07) * *$ \\
\hline Status in household & $.03(.14)$ & $.33(.11)^{* *}$ & $-.10(.11)$ \\
\hline No of household residents & $.01(.01)$ & $-.03(.01)^{* *}$ & $.01(.02)$ \\
\hline $\operatorname{Sex}(1=$ male; $0=$ female $)$ & $.05(.16)$ & $.35(.15)^{* *}$ & $-.10(.17)$ \\
\hline Age & $-.004(.003)$ & $.004(.002)^{*}$ & $-.001(.003)$ \\
\hline Binary WTP response & $1.25(.07)^{* * *}$ & $.81(.05)^{* * *}$ & $.94(.07)^{* * *}$ \\
\hline Preference for the option & $-.04(.07)$ & $.00001(.05)$ & $.002(.19)$ \\
\hline Contingent ranking of the option & $.007(.07)$ & $.05(.009) * * *$ & $-.01(.01)$ \\
\hline Constant & $5.43(.21)$ & $4.87(.23)^{* * *}$ & $5.67(.26) * * *$ \\
\hline Adjusted R-squared & .55 & .49 & .50 \\
\hline F-statistic & $33.04 * * *$ & $26.4 * * *$ & $21.59 * * *$ \\
\hline \multicolumn{4}{|l|}{ Community health workers } \\
\hline Socio-economic status & $.05(.02)^{*}$ & $.02(.02)$ & $-.01(.03)$ \\
\hline Education & $-.005(.009)$ & $.02(.01)^{* *}$ & $.01(.01)$ \\
\hline Marital status & $.25(.13)^{*}$ & $-.05(.22)$ & $.22(.18)$ \\
\hline Respondent had recent malaria & $.01(.06)$ & $-.03(.07)$ & .05 \\
\hline Status in household & $-.16(.15)$ & $.09(.14)$ & $-.11(.11)$ \\
\hline No of household residents & $-.002(.01)$ & $-.01(.02)$ & $.01(.01)$ \\
\hline $\operatorname{Sex}(1=$ male; $0=$ female $)$ & $-.13(.17)$ & $.07(.18)$ & $.03(.16)$ \\
\hline Age & $-.007(.003) * *$ & $.007(.003) *$ & $-.002(.003)$ \\
\hline Binary WTP response & $1.18(.07)^{* * *}$ & $1.14(.08)^{* * *}$ & $1.12(.07)^{* * *}$ \\
\hline Preference for the option & $-.07(.08)$ & $-.28(.20)$ & $.07(.07)$ \\
\hline Contingent ranking of the option & $.01(.01)$ & $-.02(.01)^{* *}$ & $.01(.01)$ \\
\hline Constant & $5.40(.17)$ & $5.15(.28) * * *$ & $5.23(.24) * * *$ \\
\hline Adjusted R-squared & .57 & .41 & .55 \\
\hline F-statistic & $33.78 * * *$ & $16.79 * * *$ & $26.05 * * *$ \\
\hline \multicolumn{4}{|l|}{ Primary healthcare centers } \\
\hline Socio-economic status & $.01(.02)$ & $-.01(.03)$ & $.02(.03)$ \\
\hline Education & $.0003(.009)$ & $.01(.01)$ & $-.004(.01)$ \\
\hline Marital status & $.30(.12)^{* *}$ & $-.10(.22)$ & $.10(.19)$ \\
\hline Respondent had recent malaria & $.02(.06)$ & $.06(.06)$ & $.004(.06)$ \\
\hline Status in household & $-.26(.13) * *$ & $.01(.13)$ & $-.04(.11)$ \\
\hline No of household residents & $.01(.01)$ & $.01(.01)$ & $-.01(.02)$ \\
\hline Sex $(1=$ male; $0=$ female $)$ & $-.10(.16)$ & $-.01(.17)$ & $-.02(.16)$ \\
\hline Age & $-.01(.002) * * *$ & $.002(.003)$ & $-.002(.003)$ \\
\hline Binary WTP response & $1.33(.06)^{* * *}$ & $1.05(.06)^{* * *}$ & $.94(.06)^{* * *}$ \\
\hline Preference for the option & $.06(.08)$ & $.06(.11)$ & $.34(.17) * *$ \\
\hline Contingent ranking of the option & $.02(.01)$ & $.02(.01) *$ & $.01(.01)$ \\
\hline Constant & $5.25(.19)^{* * *}$ & $5.08(.27)^{* * *}$ & $5.41(.25) * * *$ \\
\hline Adjusted R-squared & .62 & .48 & .46 \\
\hline F-statistic & $45.94 * * *$ & $25.37 * * *$ & .50 \\
\hline \multicolumn{4}{|l|}{ Patent medicine dealers } \\
\hline Socio-economic status & $-.03(.04)$ & $.09(.03)^{* *}$ & $-.03(.03)$ \\
\hline Education & $.01(.02)$ & $-.002(.01)$ & $.01(.01)$ \\
\hline Marital status & $.57(.21)^{* * *}$ & $.52(.27)^{*}$ & $.19(.19)$ \\
\hline Respondent had recent malaria & $.12(.11)$ & $.13(.08) *$ & $-.06(.06)$ \\
\hline Status in household & $-.56(.22) * *$ & $-.19(.16)$ & $-.13(.11)$ \\
\hline No of household residents & $.02(.02)$ & $-.01(.02)$ & $.003(.02)$ \\
\hline Sex $(1=$ male; $0=$ female $)$ & $-.14(.26)$ & $-.12(.20)$ & $.16(.16)$ \\
\hline Age & $-.02(.004) * * *$ & $.0001(.003)$ & $-.001(.003)$ \\
\hline Binary WTP response & $1.60(.11)^{* * *}$ & $1.33(.10)^{* * *}$ & $.91(.06)^{* * *}$ \\
\hline Preference for the option & $-.32(.18)^{*}$ & $-.02(.18)$ & $.05(.08)$ \\
\hline Contingent ranking of the option & $-.02(.03)$ & $.01(.01)$ & $.02(.01)^{*}$ \\
\hline Constant & $5.19(.31)$ & $4.76(.33)$ & $5.42(.24)$ \\
\hline Adjusted R-squared & .47 & .41 & .46 \\
\hline F-statistic & $24.66 * * *$ & $17.83 * * *$ & $18.1 * * *$ \\
\hline
\end{tabular}

Note: $* \mathrm{p}<0.10 ; * * \mathrm{p}<0.05 ; * * * \mathrm{p}<0.01$

dent of the services that are provided in public facilities in two of the communities since there is potentially better quality control, more formally trained staff, and more regulation of services there. However, it was also found that people were quite willing to pay for services of patent medicine dealers and community health workers in the study area without public health facilities (Nachi). Nonetheless, the reasons for some of these findings were not explored in this study and would be better explored using qualitative research methods in future studies. Understanding the reasoning behind consumers' 
choices could lead to better design and implementation of sustainable strategies for malaria control. ${ }^{3}$

The preferences of the people could be understood from the background of the facilities that are currently available in their communities. In Inyi and Oji where there are many existing public facilities and where the people are used to attending these facilities, the improvement of the quality of services in those facilities was the most preferred strategy for managing malaria. Conversely, in Nachi, which has no existing public health facility, the major preference was community health workers and trained patent medicine dealers. The finding that the least proportion of stating a positive WTP was for receiving treatment from trained shopkeepers and patent medicine dealers in 2 of the communities that have public health facilities could imply that previous experiences have taught the consumers to distrust this set of providers and consumers probably believed that no amount of training would lead to the provision of improved quality of services.

An approach for improving the management of malaria and to ensure equity may be to concentrate on scaling-up the strategies that were given high ranks by the most poor and average SES groups. The examination of the SES differences in the ranking also gives a guide about the management provision strategies that would be relatively improved to improve the level of equity in malaria provision and consumption. The implication of the contingent ranking of different methods for improving malaria management is that for demandresponsive malaria management services to be instituted, the delivery of services would be best undertaken through public health facilities. However, resources permitting, it should also be important to improve the quality of all or most malaria management services in the communities so as to complement one another. These may also help to improve the home management strategy for malaria. ${ }^{1,36}$

It is reassuring that the results of elicitation of WTP very closely matches the other results on preferences and contingent ranking earlier presented and this is a strong pointer to the validity of the results. The similarity of the results is a strong indication of the convergent validity of the results implying that the elicited WTP are accurate and could be used to inform policy and practice directions for improving malaria management, computing cost-benefit ratios of the different strategies, estimating potential demand, and for pricing policies. The results are apparently valid because the ranks closely mirrored the preferences. Thus, the scenario and visual analogue that were used to elicit the contingent ranks were understood by the people and could be used in similar studies and this shows that the CVM could be used to elicit valid community preferences for healthcare. ${ }^{25}$

It was interesting to find that in all provider groups, SES was positively related to WTP, amplifying the earlier results that as SES increases, level of WTP also increases. ${ }^{25}$ The overall finding that stated WTP depended on SES (or ability to pay) has been documented in previous studies. ${ }^{12,16,26,27}$ The finding that some of variables that explained the individual WTP did not have uniform effect across the study groups and 5 malaria management options, may imply that the nature of the different treatment strategies in the different study groups influenced the valuations. It has been found that patterns of treatment choice may be related to the perceptions of service quality. ${ }^{20}$ Nonetheless, the finding that many variables explained WTP could be used to argue that the findings were valid. Some of the findings with respect to the signs of the coefficients corresponded to hypothetical expectations, whereas some did not. For instance, the positive relationship of education with WTP in instances in which the relationships were statistically significant accorded with prior theoretical expectations, whereas in instances in which the relationship was non positive, it ran counter to theoretical expectations.

In conclusion, to decrease the inequity in costs of treatment and ensure the ready availability of appropriate treatment to the poorest households, the government should increase the availability of formal healthcare services for the provision of near and appropriate treatment of malaria. This strategy would decrease the financial costs (especially transportation) and maybe non-financial costs of seeking care for management of malaria and other illnesses. However, because it might not be possible for the government to construct many new health centers because of budgetary constraints, formal community health workers could be trained and planted within the villages. The community health workers should be trained and based within the communities. They should become the lowest level of primary healthcare delivery and should be paid monthly salaries.

Received January 6, 2006. Accepted for publication April 1, 2006.

Acknowledgments: We are very grateful to our research collaborators, field manager, and field workers. We are also grateful to the various community participants, especially the chiefs and malaria control people that participated in the study. The authors thank the anonymous reviewers for very helpful comments.

Financial support: This study received financial support from the UNDP/World Bank/UNICEF/WHO Special Programme for Research and Training in Tropical Diseases.

Authors' addresses: Obinna Onwujekwe, Department of Health Administration and Management, College of Medicine, University of Nigeria, PMB 01129, Enugu, Nigeria, E-mail: onwujekwe@ yahoo.co.uk. Juliana Ojukwu, Department of Paediatrics, Ebonyi State University Teaching Hospital, Abakaliki, Ebonyi State, Nigeria. Nkoli Exumah, Department of Sociology and Anthropology, University of Nigeria, Nsukka, Nigeria. Benjamin Uzochukwu, Department of Community Medicine, College of Medicine, University of Nigeria, PMB 01129, Enugu Nigeria. Nkem Dike and Eze Soludo, Health Policy Research Unit, Department of Pharmacology and Therapeutics, College of Medicine, University of Nigeria, PMB 01129, Enugu, Nigeria.

\section{REFERENCES}

1. World Health Organisation (WHO), 2000. African Summit on Roll Back Malaria, Abuja, Nigeria. WHO/CDS/RBM/2000.17. Geneva: WHO.

2. World Health Organisation (WHO), 2004. Scaling Up HomeBased Management of Malaria: From Research to Implementation. Geneva: WHO.

3. Hanson K, Goodman C, Lines J, Meek S, Bradley D, Mills A, 2004. The Economics of Malaria Control Interventions. Geneva: Global Forum for Health Research.

4. Tavrow P, Shabahang J, MaKama S, 2001. Changing harmful treatment practices among private drug sellers in rural Kenya: results of a vendor-to-vendor intervention. Book of Abstracts. The 129th Annual Meeting of the American Public Health Association. Atlanta, GA.

5. Marsh V, Mutemi WM, Muturi J, Haaland A, Watkins WM, Otieno G, Marsh K, 1999. Changing home treatment of childhood fevers by training shopkeepers in rural Kenya. Trop Med Int Health 4: 383-389.

6. Mahidol C, 2004. Malaria: integrated approaches for prevention and treatment. Editorial. Acta Trop 89: 265-269. 
7. Federal Ministry of Health (FMOH), 2001. Strategic Plan for Rolling Back Malaria in Nigeria 2001 - 2005. Abuja, Nigeria: Federal Ministry of Health.

8. Greenwood BM, Bradley AK, Greenwood AM, Byass P, Jammeh K, Marsh K, Tulloch S, Oldfield FS, Hayes R, 1987. Mortality and morbidity from malaria among children in rural area of The Gambia, West Africa. Trans R Soc Trop Med Hyg 81: 478-486.

9. Onwujekwe O, Ojukwu J, Uzochukwu B, Dike N, Shu E, 2005. Where do people from different socio-economic groups receive diagnosis and treatment for malaria in southeast Nigeria. Ann Trop Med Parasitol 99: 473-481.

10. Brieger WR, Osamor PE, Salami KK, Oladepo O, Otusanya SA, 2004. Interactions between patent medicine vendors and customers in urban and rural Nigeria. Health Pol Plan 19: 177182.

11. Kofoed PE, Rodriges A, Co F, Hedegaard K, Rombo L, Aaby P, 2004. Which children come to the health centre for treatment of malaria? Acta Trop 90: 17-22.

12. Fawole OI, Onadeko MO, 2001. Knowledge and home management of malaria fever by mothers and care givers of under five children. West Afr J Med 20: 152-157.

13. McGrath ME, 2001. Product Strategy for High Technology Companies. 2nd edition. McGraw-Hill, New York, NY.

14. Kidane G, Morrow RH, 2000. Teaching mothers to provide home treatment of malaria in Tigray, Ethiopia: a randomized trial. Lancet 356: 550-555.

15. Umar US, Olumide A, Brieger WB, 2002. Morbidity in rural southwestern Nigeria: a one year follow-up of voluntary health worker consultations in Idere, Oyo State, Nigeria. African J Med Sc 31: 297-300.

16. Kelley AG, Kelley E, Simpara CHT, Sidibe O, Makinen M, 2001. The Equity Initiative in Mali. Partnerships for Health Reform (PHR), Abt Associates Inc, Bethseda, MD.

17. Vlassof C, 1992. Listening to the people: improving disease control using social science approaches. Trans $R$ Soc Trop Med Hyg 86: 465-466.

18. Onwujekwe OE, Shu EN, Okonkwo PO, 1999. Can community leaders' preferences be used to proxy those of the community as a whole? J Health Serv Res Policy 4: 133-138.

19. Filmer D, 2005. Fever and its treatment among the more and less poor in sub-Saharan Africa. Health Policy Plan 20: 337-346.

20. Worral E, Basu S, Hanson K, 2005. Is malaria a disease of poverty? A review of the literature. Trop Med Int Health 10: 1047-1059.

21. Murray CJL, Gakidou EE, Frenk J, 1999. Health inequalities and social group differences: what should we measure? Bull World Health Organ 77: 537-543.
22. Gallup JL, Sachs JD, 2001. The economic burden of malaria. $A m$ J Trop Med Hyg 64(Suppl 1,2): 86-96.

23. Malaria and Vectors Control Unit (MVCU), 2000. Prevalence of malaria morbidity and mortality in Enugu state, 1995 to 1999. Malaria and Vectors Control Unit. Ministry of Health, Enugu, Nigeria.

24. Mitchell RC, Carson RT, 1989. Using Surveys to Value Public Goods: The Contingent Valuation Method. Washington DC; Resources for the future.

25. Donaldson C, Farrar S, Mapp T, Walker A, McPhee S, 1997. Assessing community values in health care: is the 'willingness to pay' method feasible? Health Care Anal 5: 7-29.

26. Onwujekwe OE, Fox-Rushby J, Hanson K, 2004. Valuing the benefits of a health intervention using three different approaches to contingent valuation: re-treatment of mosquito bed-nets in Nigeria. J Health Ser Res Pol 9: 67-75.

27. Onwujekwe OE, 2004. Criterion and content validity of a novel structured haggling contingent valuation question format versus the bidding game and binary with follow-up questions. Soc Sci Med 58: 525-537.

28. Diamond P, Hausman J, 1994. Contingent valuation: Is some number better than no number? J Econ Perspec 8: 45-64.

29. Stavem K, 2002. Association of willingness to pay with severity of chronic obstructive pulmonary disease, health status and other preference measures. Int J Tub Lung Dis 6: 542-549.

30. Liljas B, Blumenschein K, 2000. On hypothetical bias and calibration in cost-benefit studies. Health Policy (New York) 52: 53-70.

31. Currie GR, Donaldson C, O'Brien BJ, Stoddart GL, Torrance GW, Drummond MF, 2002. Willingness to pay for what? A note of alternate definitions of health care program benefits for contingent valuation studies. Med Decis Making 22: 493 497.

32. Shackley P, Donaldson C, 2002. Should we use willingness to pay to elicit community preferences for health care? New evidence from using a 'marginal' approach. J Health Econ 21: 971-991.

33. Mathiyazhagan K, 1998. Willingness to pay for rural health insurance through community participation in India. Health Plan Manage 13: 47-67.

34. Frykblom $\mathrm{P}, 1997$. Hypothetical question modes and real willingness to pay. J Environ Econ Manage 34: 275-287.

35. Bloland PB, Kachur SP, Williams HA, 2003. Trends in antimalarial drug deployment in sub-Saharan Africa. J Exp Biol 206: 3761-3769.

36. TDR, 2002. Scaling up home management of malaria. Keynote article. TDR News No. 67: 1-2. 